\title{
Para além da qualificação profissional
}

Sílvio Gallo ${ }^{1}$

presente número de Filosofia e Educação contempla e
estampa um dossiê composto por um conjunto de sete
artigos, originalmente apresentados no II Congresso da Sociedade Brasileira de Filosofia da Educação, sediado na Faculdade de Educação da Universidade Estadual de Campinas nos dias 14 e 15 de setembro de 2016. Os artigos foram escolhidos pela comissão organizadora e pelo comitê científico do evento dentre os quase cem textos aprovados para apresentação como comunicação oral no evento. São de autoria de professores e pesquisadores de diferentes universidades de distintas regiões brasileiras.

Criada a partir do GT Filosofia da Educação da Associação Nacional de Pós-Graduação e Pesquisa em Educação (ANPEd), a SOFIE - Sociedade Brasileira de Filosofia da Educação - realizou seu primeiro congresso entre os dias 10 e 12 de setembro de 2014 na Universidade de Passo Fundo/RS, conjuntamente com o V Seminário Internacional sobre Filosofia e Educação, promovido pela UPF. Como forma de consolidar a Associação, assim como dando-lhe maior visibilidade, seu II Congresso foi realizado de forma autônoma, sendo constituído de conferências, mesas redondas e sessões de comunicações orais, bem como por sessões de apresentações de pôsteres.

${ }^{1}$ Professor Titular da FE-Unicamp e presidente da SOFIE. 
O tema escolhido por sua diretoria, Filosofia da Educação: entre a formação de educadores e a qualificação profissional, teve por objetivo sistematizar os debates que vêm sendo realizados pelo campo da Filosofia da Educação tanto no Brasil (durante várias reuniões o GT Filosofia da Educação da ANPEd debateu diferentes aspectos da questão) quanto no Exterior. Visou também oferecer ferramentas conceituais e teóricas para que os filósofos que se dedicam à educação possam participar ativamente do debate nacional em torno da problemática formativa, em suas várias instâncias. $\mathrm{O}$ viés crítico da proposta é evidenciado na perspectiva de debater a formação no contrafluxo dos processos de qualificação profissional, tomados num sentido estritamente técnico. A SOFIE pretende construir subsídios teóricos para compreender a formação de modo amplo, para além do estritamente profissional. Não se trata de desprezar a formação profissional; ao contrário, trata-se de reivindicar a importância da Filosofia também nesse âmbito formativo.

Conhecemos discursos recorrentes em torno da afirmação da importância da Filosofia nos mais variados âmbitos e níveis formativos; mas temos acompanhado, também, o fenômeno de sua dispersão e mesmo desaparecimento em vários cursos, como as Licenciaturas, as graduações em Pedagogia, em certos cursos de formação profissional, seja em nível médio ou superior. Cada vez menos espaço é destinado para as humanidades de forma geral e para a Filosofia de modo particular nos desenhos e engenharias curriculares destes cursos. Parece então, para a SOFIE, de fundamental importância colocar em cena um debate em torno deste fenômeno que, 
de um lado, afirma a importância formativa da Filosofia e, de outro, reduz ou mesmo elimina sua presença nos espaços formativos.

Os textos do dossiê possuem em comum uma abordagem centrada em Filosofia contemporânea. Mas debruçam-se sobre diferentes aspectos do fenômeno formativo, ora abordando-o de forma direta, ora tocando-o indiretamente.

Eldon Henrique Mühl e Elisa Mainardi, docentes da Universidade de Passo Fundo, problematizam o lugar da Filosofia nos cursos de Pedagogia, no artigo A Filosofia da Educação nos cursos de Pedagogia do Brasil - da obrigatoriedade à dispensa progressiva. As reflexões apresentadas no artigo partem de uma pesquisa que investigou as Diretrizes do Curso de Pedagogia no país, desde suas origens, mostrando o progressivo descompromisso com as dimensões teóricas da formação, a Filosofia aí compreendida, e estão direcionadas para uma tentativa de retomada das contribuições que ela pode trazer para a formação dos pedagogos.

No artigo A Formação do professor em Filosofia no Brasil: restrição de pensamento e testemunho, Tiago Brentam Perencini, pesquisador e doutorando na Unesp-Marília, problematiza a formação do professor de Filosofia. O artigo articula uma "visão testemunhal" com resultados de pesquisa. De um lado, o autor interroga sua própria história, como estudante de graduação em Filosofia, como pesquisador de um mestrado em Educação no qual dedicou-se ao ensino desta disciplina no Brasil e atualmente como doutorando, buscando compreender os aspectos formativos do professor de Filosofia no país, num contexto em que a dedicação ao magistério parece desprezada na área. De outro lado, são trabalhados aspectos 
dessa formação a partir dos dados empíricos obtidos em sua pesquisa de mestrado, que investigou periódicos publicados no período de criação das universidades no país, ali buscando textos que refletissem a problemática do ensino da Filosofia. Suas conclusões apontam para uma debilidade em torno da formação docente em Filosofia, mas também para a formação docente em geral, e abre campos de reflexão importantes para a contemporaneidade.

A prática reflexiva e professor em formação, artigo de autoria de Darcísio Natal Muraro, docente da Universidade Estadual de Londrina, debruça-se sobre um dos mais importantes filósofos da educação, John Dewey, para pensar a formação do professor como prática reflexiva. Tomando a educação como "desenvolvimento da capacidade de pensar reflexivo como método de aprender através de uma experiência", questiona como a experiência da reflexividade impacta os processos formativos dos professores. Os aspectos políticos e éticos são postos em destaque, no contexto de uma Filosofia da Educação pensada como prática da democracia.

José Rogério Vitkowski, docente na Universidade Estadual de Ponta Grossa, no artigo Filosofia da diferença: interfaces educacionais, busca na Filosofia da diferença, em especial aquela produzida por Deleuze na esteira de Nietzsche, elementos para pensar o campo problemático da educação. $\mathrm{O}$ texto dedica-se, sobretudo, a problematizar a própria Filosofia, e após apresentar algumas concepções, centra-se na compreensão exposta por Deleuze \& Guattari, de que essa disciplina do pensamento consiste na atividade de criação conceitual. Em suas considerações finais, são pensadas interfaces possíveis com o campo educativo. 
A pesquisadora Paola Sanfelice Zeppini, doutora em Educação pela Unicamp, em Questionamentos sobre uma educação problematizante: pedagogia do conceito e possibilidades de resistência, visita o pensamento de Gilles Deleuze e sua noção de uma "pedagogia do conceito" para pensar a natureza de uma educação problematizante. O filósofo francês argumentou em torno do problema como sendo aquilo que provoca o pensamento e que leva à produção do conceito; em seu artigo, a autora extrapola a dimensão do estritamente filosófico, interrogando-se em torno dos papeis que a problematização joga no âmbito educativo. $\mathrm{O}$ texto apresenta contribuições importantes sobre as contribuições de uma postura filosófica problematizante em educação e as possibilidades formativas que ela abre neste contexto.

Maria Emanuela Esteves dos Santos, docente na Universidade Federal de São João del Rey contribui com o artigo intitulado Filosofia da Educação e pensamento das multiplicidades em Michel Serres. A obra do filósofo contemporâneo francês é perscrutada no intento de compreender sua noção de multiplicidade como teoria da comunicação, base para se pensar uma relação nas diferenças, como elemento apropriado para o mundo contemporâneo. Tal teoria das multiplicidades é mobilizada para pensar o que a autora denomina um 'a'fundamento da educação, introduzindo uma linha de pensamento de uma Filosofia da Educação que não seja fundacionista ou fundamentalista, mas que seja pensada como elemento diferencial no contexto do múltiplo. Tal perspectiva pode impactar positivamente o terreno da Filosofia da Educação contemporânea, abrindo novas possibilidades de contribuição para os processos formativos. 
A bravura do gosto é o título emblemático e provocante o artigo de Lúcia Schneider Hardt, Rosana Silva de Moura e Rodrigo Mafalda. As duas primeiras são docentes da Universidade Federal de Santa Catarina e o terceiro autor é doutorando na instituição. O tema do gosto é pensado, em princípio, com Nietzsche e seus comentários da obra de Wagner, para em seguida ser direcionado ao campo da educação. Como o gosto impacta os processos educativos? Ou não impacta? O projeto é ambicioso: tensionar os processos formativos, que não podem ser compreendidos de forma única ou unificada, através de uma postura dionisíaca, que traga um pouco de caos e de vida para uma instância que costuma ser organizada e ordenada, talvez em demasia.

O conjunto de textos que ora apresentamos são uma mostra daquilo que foi apresentado em 21 sessões de comunicações orais apenas uma pequena parte desse vasto panorama de interrogação e de reflexão. Como afirmamos antes, entendemos ser papel da SOFIE fazer circular essas ideias e ampliar cada vez mais o debate. O presente dossiê faz parte desse esforço e junta-se a outras publicações decorrentes do II Congresso da Sociedade Brasileira de Filosofia da Educação.

A diretoria da SOFIE agradece à Editoria da Revista Filosofia e Educação o acolhimento da proposta de publicação deste dossiê, somando-se a nossos esforços de manter viva a prática filosófica em educação no país. 